\title{
Anti-obesity effects of green tea extracts on humans
}

\author{
K A Naser ${ }^{1}$, D Niyangoda², R Wijesinghe ${ }^{3}$ \\ Sri Lanka Journal of Diabetes, Endocrinology and Metabolism 2015; 5: $42-50$
}

\begin{abstract}
Introduction: Green tea is heavily promoted and sold over the counter for many illnesses, including obesity.

Methodology: Literature was reviewed focusing on the key words; tea, green tea, catechin, overweight, obesity, side effects, adverse effects, transient ischemic attack, stroke and liver function, up to December 2014.

Results and discussion: Majority of the studies on this topic were short term and involved only a small number of participants. Though these studies demonstrated very small reduction of weight, evidence was inadequate for the use of green tea as an anti-obesity agent. In this review, the effect of green tea on obesity and some possible harmful effects of green tea are discussed. Current evidence on green tea does not support the use of it as an anti-obesity agent. There are several reports of side effects. The liver side effects are a cause for concern.
\end{abstract}

Conclusions: Long term use of green tea as over the counter supplement should not be encouraged. Rather it should be considered a drink, very much like any other tea or coffee, till further evidence of efficacy and safety are proven.

Key words: green tea, catechin, caffeine, overweight and obesity

\section{Introduction}

Obesity, the most prevalent metabolic disease worldwide, affects adults, adolescents and children by reaching epidemic proportions. Obesity is an excess of adipose tissue in relation to lean body mass. Body mass index (BMI) and waist circumference (WC) are used as surrogates for adiposity, on routine examinations (1). Obesity, especially central obesity is a risk factor for number of chronic diseases, including type 2 diabetes mellitus, ischaemic heart disease and hypertension $(1,2)$. Modest weight loss at $5-10 \%$ of the initial body weight, leads to reduction of risk of mortality and morbidity that have been linked with obesity and is a realistic goal $(1,3)$.

Judicial use of dietary agents combined with physical activity and reduction of energy consumption are safer than the surgical and pharmacological methods in controlling obesity $(2,4)$. Green tea, a non-fermented tea prepared by tea (Camellia sinensis, Theaceae) leaves, is a functional food ingredient and has been reported to have anti-obesity properties. Worldwide people consume this tea on a daily basis as a beverage, especially in Asian countries. Green tea, a dietary agent has been reported to be effective in prevention of obesity by epidemiological and laboratory studies (2, 5-8). However, it has been found that it imparts some harmful effects such as hepatotoxicity if consumed in large quantities for a long period of time. Anti-obesity effects of green tea on humans are discussed in this review.

\section{Methodology}

Literature was reviewed focusing on the key words; tea, green tea, catechin, overweight, obesity, side effects, adverse effects, transient ischaemic attack, stroke and liver function up to December 2014. Discussion is targeted on obesity, composition of green tea, mechanism of action, epidemiological and interventional studies, body weight maintenance, pharmacokinetics, harmful effects and transient ischemic attack.

\section{Results and discussion}

\section{Composition of green tea}

Tea (Camellia sinensis, Theaceae) is the most popular beverage next to water, consumed by over two-

${ }^{1}$ Sherwood forest NHS foundation trust, Mansfield, UK, ${ }^{2}$ Department of pharmacy, faculty of allied health sciences, university of Peradeniya,Sri Lanka, ${ }^{3}$ Postgraduate institute of science, university of Peradeniya, Sri Lanka. 
third of the world's population (4, 5, 9, 10). The main types of tea; black, oolong and green tea differ in terms of processing and chemical composition. Green tea is prepared by initial heating to inactivate the endogenous enzymes, while oolong and black tea are fermented. Tea leaves contain main energy sources; protein, carbohydrate, lipids and other health beneficial and flavoring components such as polyphenols, tannins, vitamins, minerals, volatile compounds, pigments and caffeine. Polyphenols and caffeine, the main components in a cup of tea are responsible for astringency and refreshment, respectively (11-13). Catechin, a colorless polyphenol is highly present in leaves at harvest and varied with the processing conditions and the variety of tea. Green tea preserves a large amount of catechins from oxidation than of others due to absence of fermentation step in processing (9). Furthermore, the amount of catechins in a cup of tea is highly variable, depending on preparation method adopted including the ratio of dry tea to water, temperature of water and the immersion time of leaves in hot water (9, 14-16).

Tea contains four major catechins; (-)-epicatechin (EC), (-)-epigallocatechin (EGC), (-)-epicatechin-3-gallate (ECG), and (-)-epigallocatechin-3-gallate (EGCG). EGCG is the most abundant and possesses the most potent antioxidative activity $(2,6,14,17-20)$. A cup of green tea contains 50-150 mg of catechins and 7.8-30 mg of caffeine (9, 21-23). Canned tea contains $0.3-35 \mathrm{mg}$ of catechins/100 $\mathrm{mL}$ (24). Iced tea was found not to contain any flavanols (25). Average green tea catechin consumption in United Kingdom (200 mL cup) is $405.5 \mathrm{mg} /$ day and in Japan (120 mLcup) is $200-400 \mathrm{mg} /$ day $(23,26)$.

According to label claims, commercially available green tea formulations supply 150-800 mg catechins/day, 22.5-700 mg EGCG/d and 5.5-8.0 mg caffeine/day when taken as recommended. However, measured catechins contents were found to be $9-48 \%$ though the label claimed $100 \%$, according to a study conducted in USA (27-32).

\section{Mechanism of action}

Physiological functions of catechins are mainly ascribed to the gallate esters of 'epi' catechins $(7,10)$. Potential mechanisms by which catechins prevent development of overweight and obesity involve inhibition of adipocyte differentiation and proliferation, reduced fat absorption, inhibition of gastric and pancreatic lipases, increased energy expenditure and fat oxidation via stimulating thermogenesis by inhibition of catechol-omethyl-transferase (COMT) which is a catecholaminedegrading enzyme, synergism with caffeine and suppression of fatty acid synthesis $(17,14,33-37)$.

COMT inhibitory activity is possessed by all gallatecatechins and is highest for EGCG, a non-competitive inhibitor with half maximal inhibitory concentration ( IC $_{50}$ ) of 70nM (38). However, inter-individual variability of COMT activity could vary as much as threefold and the effects of catechins on energy expenditure may vary depending on genetic variability in COMT activity (14, $39,40)$. Besides, there is a large subject-to-subject variability in the pharmacokinetics of catechins (41).

\section{Epidemiological and interventional studies}

Green tea is widely consumed in China, Japan, Korea and Morocco. Green tea has been considered by the traditional Chinese medicine as a healthful beverage. An epidemiological study revealed that $43 \%$ of Chinese were habitual tea drinkers and $96 \%$ of them were green or oolong tea consumers (42). The authors of this study found that longer the duration of tea consumption, lower the percent body fat, waist circumference (WC), hip circumference, and waist-to-hip ratio. Short term (375 mg catechins/d and $150 \mathrm{mg}$ caffeine/d) as well as long term (570.4 mg catechins/ $\mathrm{d}$ with regular exercise for 2 months) consumption of green tea increases fat utilization and energy expenditure in sedentary conditions $(43,44)$. The effect of EGCG (300 $\mathrm{mg} / \mathrm{d}$ for 2 days) on fat oxidation is higher under postprandial than fasting conditions in men (45). Long term ingestion of tea catechins stimulates dietary induced thermogenesis and dietary fat oxidation (34).

Two hundred and seventy (270) mg/d EGCG with 600 mg of caffeine a day has been reported to be the optimal concentration to produce an effect on macronutrient oxidation and to increase energy expenditure in sedentary conditions $(46,47)$. Beyond this threshold, the EGCG content of a compound containing a fixed dose of caffeine $(600 \mathrm{mg} / \mathrm{d})$ only produces a small non-significant additional increase in $24 \mathrm{~h}$ energy expenditure (46). However, the caffeine dose used here is twice as the habitual caffeine intake and may hinder the effects of EGCG. Table 1.0 shows the effect of different quantities of catechins and caffeine in tea on percentage body weight reduction of humans. Above studies show that $491 \mathrm{mg}$ catechins/day resulted in lesser reduction in percentage of weight than 468, 458 and $444 \mathrm{mg}$ catechins/day (9, 48, 49). The considerable higher percentage of weight loss with 666 mg catechins/day than with $680 \mathrm{mg}$ EGCG/day may be due to lower body mass index (BMI) of subjects and the synergistic effect of all the catechins rather than from EGCG only $(50,51)$. BMI ranges of subjects used by Maki et al. were wider and they lost more weight $(2.2 \mathrm{~kg})$ than the subjects in the other study $(1.7 \mathrm{~kg})$, although both 625 and $583 \mathrm{mg}$ catechins/day have shown similar weight reduction $(20,52)$.

Hsu et al. studied Tai women having 27.6>BMI<34.8 and the subjects had ingested capsules containing green tea extract three times daily 30 min after a meal (48). In other two studies Japanese adults had ingested beverages twice daily with meal $(9,49)$. BMIs of the subjects ranged from 22.5-30 with Kajimoto et al. and 24-35 with Wang et al. 
Table 1. Effect of green tea on body weight reduction

\begin{tabular}{|c|c|c|c|c|}
\hline \multicolumn{2}{|c|}{ Composition } & \multirow{2}{*}{$\begin{array}{c}\text { Intake period/ } \\
\text { week }\end{array}$} & \multirow{2}{*}{$\begin{array}{l}\text { Body weight } \\
\text { reduction } / \%\end{array}$} & \multirow[t]{2}{*}{ Reference } \\
\hline Catechin/ $(\mathrm{mg} / \mathrm{d})$ & caffeine/ $(\mathrm{mg} / \mathrm{d})$ & & & \\
\hline 172 (EGCG) & 138 & 06 & $1.6^{\mathrm{s}}$ & Bajerska et al., 2010 [50] \\
\hline 236 & 97 & 24 & $1.5^{\mathrm{NS}}$ & Stendell-Hollis et al., 2010 [53] \\
\hline 300 (EGCG) & $\begin{array}{c}\text { low habitual } \\
\text { caffeine intake }\end{array}$ & 12 & $0.1^{\mathrm{NS}}$ & Hill et al., 2007 [47] \\
\hline 444 & 50 & 12 & $0.7^{\mathrm{s}}$ & Kajimoto et al., 2005 [49] \\
\hline 458 & 104 & 12 & $1.0^{\mathrm{NS}}$ & Wang et al., 2010 [9] \\
\hline 468 & 126 & 12 & $1.0^{\mathrm{NS}}$ & Wang et al., 2010 [9] \\
\hline 491 & 27.3 & 12 & $0.3^{\mathrm{NS}}$ & Hsu et al., 2008 [48] \\
\hline 583 & 130 & 12 & $2.3^{\mathrm{s}}$ & Nagao et al., 2007 [20] \\
\hline 625 & 115 & 12 & $2.3^{\mathrm{s}}$ & Maki et al., 2009 [52] \\
\hline 665.9 & 50 & 12 & $1.0^{\mathrm{s}}$ & Kajimoto et al., 2005 [49] \\
\hline 680 (EGCG) & 49 & 06 & $0.8^{\mathrm{s}}$ & Bajerska et al., 2010 [50] \\
\hline 690 & 75 & 12 & $3.2^{\mathrm{s}}$ & Nagao et al., 2005 [27] \\
\hline 886 & 198 & 12 & $1.7^{\mathrm{s}}$ & Wang et al., 2010 [9] \\
\hline
\end{tabular}

S- Significant and NS- Non-significant at $\mathrm{p}<0.05$

$(9,49)$. High catechin:caffeine ratio given by Hsu et al. and low bioavailability of catechins when given as capsules compared to the beverage form may have caused lesser reduction in percentage body weight (48). Furthermore, Tai women may be less sensitive to catechins.

Two hundred and thirty six (236) mg catechins/day caused $1.5 \%$ weight reduction while $458 \mathrm{mg}$ catechins/ day accounted for $1 \%$ reduction $(9,53)$. This can be justified by longer duration of treatment with frequent dosing which had led to stable catechin and caffeine plasma concentrations, by Stendell-Hollis et al., compared to Wang et al. $(9,53)$.

All these studies have been of short duration, most lasting 12 weeks. Most of the research have failed to show a clinically significant, i.e. 5-10\%, weight loss. However, $5.5 \%$ and $14.3 \%$ weight losses have been reported by Diepvens et al. and Pierro et al., respectively $(38,54)$. In the former study, reduction was due to $1207 \mathrm{mg}$ catechins/ day and $300 \mathrm{mg}$ caffeine/day with hypocaloric diet in healthy females while the latter was due to $300 \mathrm{mg} /$ day of Monoselect Camellia ${ }^{\circledR}$ (a preparation containing a standardized green tea extract complexed with phospholipids amount of catechins was not cited) with hypocaloric diet $(38,54)$. However, when compared with placebo, green tea has no effect on body weight or body composition (54).

Table 2 shows the WC reduction in several studies with catechins. Significant decrease in total fat area was observed with the doses of 690, 666 and $444 \mathrm{mg}$ catechins/ day; reduction in visceral fat area with 666, 583 and 444 $\mathrm{mg}$ catechins/day were observed; reduction in subcutaneous fat area was observed with 690 and $583 \mathrm{mg}$ catechins/day; and reduction in abdominal fat area was observed with $625 \mathrm{mg}$ of catechins/day during exercise $(20,27,49,52)$.

Catechins render better results on body weight and WC when combined with dietary control, physical activity and caffeine intake than ingesting catechins alone. Furthermore, maintaining the ratio of catechins:caffeine around 1:1 is important in weight reduction strategies (50).

\section{Body weight maintenance}

Habitual high caffeine (270 mg EGCG + 150 mg caffeine/day) consumption was found to reduce the body weight, fat mass and WC more than in low caffeine consumption, through thermogenesis and fat oxidation. Weight maintenance after weight loss was not affected by green tea, supplying caffeine ( $104 \mathrm{mg} / \mathrm{d})$ and catechins (573 mg/d) for 13 weeks, in overweight and moderately obese humans (55). However, habitual high caffeine consumption was associated with a higher weight regain compared with habitual low caffeine consumption (55).

Administration of EGCG and caffeine with diet supplying $\approx 10 \%$ total energy from protein is effective for weight maintenance following weight loss in overweight and moderately obese humans (3). However, considerably 
Table 2. Effect of green tea on WC reduction

\begin{tabular}{lccrr}
\hline \multicolumn{2}{c}{ Composition } & & WC & \multicolumn{1}{c}{ Reference } \\
\cline { 1 - 1 } Catechin/ $(\mathrm{mg} / \mathrm{d})$ & caffeine/ $(\mathrm{mg} / \mathrm{d})$ & & reduction/cm & \\
\hline 236 -6 months & - & $0.9^{\mathrm{Ns}}$ & Stendell-Hollis et al., 2010 [53] \\
300 (EGCG) & - & $1.0^{\mathrm{s}}$ & Hill et al., 2007 [47] \\
375 in an uncontrolled study & - & $4.1^{\mathrm{Ns}}$ & Chantre et al., 2002 [33] \\
444 & - & $0.9^{\mathrm{s}}$ & Kajimoto et al., 2005 [49] \\
458 & 104 & $1.1^{\mathrm{Ns}}$ & Wang et al., 2010 [9] \\
468 & 126 & $1.3^{\mathrm{Ns}}$ & Wang et al., 2010 [9] \\
491 & - & $1.7^{\mathrm{s}}$ & Hsuet al., 2008 [48] \\
583 & - & $0.7^{\mathrm{s}}$ & Nagao et al., 2007 [20] \\
625 & - & $0.9^{\mathrm{Ns}}$ & Maki et al., 2009 [52] \\
666 & - & $0.8^{\mathrm{s}}$ & Kajimoto et al., 2005 [49] \\
690 & 75 & $3.4^{\mathrm{s}}$ & Nagao et al., 2005 [27] \\
886 & 198 & $1.9^{\mathrm{s}}$ & Wang et al., 2010 [9] \\
1207 & - & $4.5^{\mathrm{s}}$ & Diepvens et al., 2006 [54] \\
\hline
\end{tabular}

S- Significant and NS- Non-significant at $\mathrm{p}<0.05$

high level of hunger and lower satiety were reported in this diet and may result in weight gain with additional intake of meals or snacks (3). Although both green teacaffeine mixture and high protein diets have proven to be effective in weight maintenance followed by weight loss, synergistic effect has not been reported (3).

\section{Pharmacokinetics}

After ingestion peak plasma concentrations $\left(\mathrm{C}_{\max }\right)$ of catechins were reached rapidly and gradually reduced to undetectable levels in $24 \mathrm{~h}(19,56,57)$. $\mathrm{C}_{\max }$, time to reach $\mathrm{C}_{\max }$ and elimination half-life of EGCG rise in a dose dependent manner $(19,41)$. Caffeine or other catechins have been reported to affect the pharmacokinetics of EGCG $(19,74)$. Bioavailability of EGCG is higher than that of EGC and EC (19).

Oral bioavailability of catechins from supplements exceeds that of brewed tea (14). A significant fraction of the orally administered catechins is eliminated presystemically or is decomposed during intestinal absorption and in blood $(11,19,41)$. This can result from ingestion of catechins with meals, transportation of absorbed EGCG back into intestine by P-gp, multi drug resistance gene product, and/or ionization of catechins when stomach $\mathrm{pH}$ is increased $(3,11,39,41)$. In contrast, Van het Hof et al. found that addition of skimmed milk has no effect on bioavailability of catechins (56). However, the percentage of milk added to tea used in this study is lower than that used in previous studies (56). Catechins were found in human saliva, blood and urine after mouth rinsing and oral administration of catechins as solutions (11).

The catechins are metabolized by the liver and kidneys, and excreted in bile and urine (11). They are subjected to extensive biotransformation including methylation, glucuronidation, sulfation and ring-fission metabolism (11). In plasma, EGCG and ECG have been reported to be mostly present in the free form $(41,57)$. EGC and EC have been detected in plasma and urine, predominantly as glucuronic acid and sulfate conjugates (19). Free EC levels were very low or undetectable in plasma $(19,41)$. In physiological conditions, it is very likely that EGCG is oxidatively decomposed, but not (+)catechin (11). The decomposition of EGCG and EGC was found in a short time, even at $\mathrm{pH} 7.4$ (11).

\section{Harmful effects}

Green tea has been widely consumed in China and Japan for many centuries and is generally regarded safe (39). Table 3.0 summarizes the health effects of green tea intake in different quantities of catechins, caffeine and flavanols.

However, several cases were reported on hepatotoxicity of green tea intake in different products consumed for $\geq 1$ month as shown in Table 4 . In all cases, patients had taken the relevant product of green tea extract for weight maintenance and had not any history of liver disease, alcohol use and risk factors for viral hepatitis. According to case reports of consumption of 
Table 3. Effect of green tea on health

\begin{tabular}{|c|c|c|c|}
\hline Composition/ (mg/d) & $\begin{array}{l}\text { Time duration } \\
\text { of the intake }\end{array}$ & Health effects & Reference \\
\hline 886 catechins and 198 caffeine & 90 days & No differences of liver function tests & Wang et al., 2010 [9] \\
\hline 844 catechins & 14 days & $\begin{array}{l}\text { Alter the activity of the enzymes } \\
\text { cytochrome P-450 2D6 and 3A4 }\end{array}$ & Donovan et al., 2004 [58] \\
\hline 800EGCG & 4 weeks & $\begin{array}{l}\text { No alteration of phenotypic indices } \\
\text { of CYP1A2, CYP12D6, and CYP12C9, } \\
\text { but resulted in a small reduction in } \\
\text { CYP3A4 activity }\end{array}$ & Chow et al., 2006 [59] \\
\hline 670 flavanols & 3 weeks & $\begin{array}{l}\text { No alterations of markers of liver } \\
\text { and kidney function in healthy men }\end{array}$ & Frank et al., 2009 [60] \\
\hline 625 catechins and 39 caffeine & 12 weeks & No liver toxicity & Maki et al., 2009 [52] \\
\hline 666 catechins & & & Kajimoto et al., 2005 [49] \\
\hline 800EGCG & 4 weeks & $\begin{array}{l}\text { No significant changes in blood } \\
\text { counts and blood chemistry profiles }\end{array}$ & Chow et al., 2003 [57] \\
\hline 300EGCG & 12 weeks & No adverse effects & Hill et al., 2007 [47] \\
\hline 583 catechins & 12 weeks & & Nagao et al., 2007 [20] \\
\hline Population based study, Japan & & $\begin{array}{l}\text { No significant association between liver } \\
\text { cancer risk and green tea consumption }\end{array}$ & Inoue et al., 2009 [61] \\
\hline $\begin{array}{l}\text { Increased consumption of } \\
\text { green tea, meta analysis }\end{array}$ & & Reduce the risk of liver disease & $\begin{array}{r}\text { Jin et al., } 2008 \text { [62] } \\
\text { Sing et al., } 2011 \text { [63] }\end{array}$ \\
\hline
\end{tabular}

green tea-based supplements, histological examination revealed inflammatory, cholestatic or necrotic liver damage depending on the subject (2). In $\sim 20 \%$ of case reports, additional liver damage following re-challenge with the same preparation was observed (2). However, no clear determinants for the type of pathology observed have been reported (2). US Pharmacopoeia Dietary Supplements Information Expert Committee has proposed that all green tea extract products should bear a label that suggests consumption together with food because of the possibility of severe liver problems (17).

Oral bolus dosing results in greatly increased $\mathrm{C}_{\max }$ of EGCG compared with dietary administration and divided doses of the same total daily dose $(2,57)$. Caffeine content, presence of aluminum, and the affinity of catechins on iron are the major harmful effects of over consumption of tea (5). Green tea extracts may exert diuresis, excess gas, nausea, heartburn, stomachache, abdominal pain, diarrhea, dizziness, headache, muscle pain, increased levels of transaminases and serum bilirubin, blood pressure elevation and decreased dietary iron absorption (2, 5, 33, 46, 57). The incidence of gastrointestinal adverse events increased at higher doses under fasting conditions and with bolus dosing $(41,57)$. Green tea consumption is not advisable in cases of special sensitiveness to xanthic bases (5). Negative effects produced by caffeine are nervousness, sleep disorders, vomiting, headache, epigastric pain, tachycardia, palpitation, anxiety, restlessness, dizziness and high blood pressure $(5,39)$. Even though, acute caffeine consumption may alter some cardiovascular variables, chronic ingestion of caffeine has little or no health consequences (39).

Supplements of green tea contain much higher catechin and caffeine doses than green tea beverages, in different dosage forms and may cause harmful effects (2). One capsule has been reported to be equal to 5-7 cups of tea. Theses capsules are usually taken more than one a day. Furthermore, United Kingdom tea council has recommended intake of 3-4 cups of tea per day for health benefits and intake of $>6$ cups of tea is not beneficial to health (58-63).

\section{Green tea and transient ischemic attack}

A meta analysis from nine studies involving 4378 
Table 4. Hepatotoxicity of green tea extract

\begin{tabular}{|c|c|c|c|c|c|}
\hline Composition & Age/year & Gender & $\begin{array}{l}\text { Time duration } \\
\text { of the } \\
\text { intake/Month }\end{array}$ & Harmful effect & Reference \\
\hline $\begin{array}{l}720 \mathrm{mg} / \text { day green tea } \\
\text { extract }\end{array}$ & 44 & Female & 6 & $\begin{array}{l}\text { Acute liver toxicity } \\
\text { with hepatitis }\end{array}$ & $\begin{array}{r}\text { Molinari et al., } \\
2006 \text { [66] }\end{array}$ \\
\hline Green tea extract & 37 & Female & 4 & $\begin{array}{l}\text { Nausea, abdominal pain } \\
\text { and jaundice }\end{array}$ & Bonkovsky, 2006 [67] \\
\hline $\begin{array}{l}\text { 'Hydroxycut'; green tea } \\
\text { extract }\end{array}$ & 27 & Male & 1 & Fatigue and jaundice & Stevens et al., 2005 [68] \\
\hline $\begin{array}{l}\text { 'Euphoria’; herbal product } \\
\text { including green tea }\end{array}$ & 45 & Female & 1 & Jaundice & $\begin{array}{r}\text { Jimenez-Encarnacion } \\
\text { et al., } 2012 \text { [69] }\end{array}$ \\
\hline $\begin{array}{l}\text { 'SlimQuick'; herbal } \\
\text { product including green tea }\end{array}$ & 24 & Female & 3 & Jaundice & Weinstein et al., 2012 [70] \\
\hline 'Fat burners'; green tea & 28 & Female & 1 & Jaundice & Krishna et al., 2011 [71] \\
\hline 'Hydroxycut' or & 31 & Female & 3 & Jaundice & Chen et al., 2010 [72] \\
\hline $\begin{array}{l}\text { 'Herbalife' products; green } \\
\text { tea extract }\end{array}$ & $\begin{array}{l}37 \\
53\end{array}$ & & $\begin{array}{c}4 \\
12\end{array}$ & & \\
\hline $\begin{array}{l}\text { 'Hydroxycut'; green tea } \\
\text { extract }\end{array}$ & 23 & Female & 2 & Jaundice & Rashid and Grant, 2010 [73] \\
\hline
\end{tabular}

strokes among 194, 965 individuals has revealed that daily consumption of either green or black tea equaling three cup per day could prevent the onset of ischemic stroke (64). Furthermore, regardless of their country of origin, individuals consuming $\geq 3$ cups of tea per day had a $21 \%$ lower risk of stroke than those consuming $<1$ cup per day (absolute risk reduction, 0.79; CI, 0.73 to 0.85) (64).

However, according to a case report, transient ischemic attack-like symptoms could possibly be attributed to one or more components of oolong tea, especially when consumed in large quantities (65).

\section{Conclusions}

Catechins render a very modest effect on reducing body weight and waist circumference when combined with dietary control, physical activity and caffeine intake than ingesting catechins alone. However, $300 \mathrm{mg} / \mathrm{d}$ of Monoselect Camellia ${ }^{\circledR}$ is the only preparation that showed a clinically and statistically significant weight loss (14.3\%). Nevertheless, this study was conducted with hypocaloric diet. Except very few studies most have been conducted for twelve week duration. Hence, further large randomized, long term studies are needed to determine whether this product demonstrates an antiobesity effect with or without hypocaloric diet. Contrasting results have been found when green tea is used to maintain weight following weight loss. Current evidence on green tea does not support the use of it as an anti-obesity agent. There are several reports of side effects. The liver side effects are a cause for concern. Therefore long term use of green tea as over the counter supplement should not be encouraged. Rather it should be considered a drink, very much like any other tea or coffee, till further evidence of efficacy and safety are proven.

\section{References}

1. Tsigos C, Hainer V, Basdevant A, et al. Management of obesity in adults: European clinical practice guidelines. Obesity Facts 2008; 1: 106-14.

2. Grove KA, Lambert JD. Laboratory, epidemiological, and human intervention studies show that tea (Camellia sinensis) may be useful in the prevention of obesity. Journal of Nutrition 2010; 140: 446-51.

3. Hursel R, Westerterp-Plantenga MS. Green tea catechin plus caffeine supplementation to a high-protein diet has no additional effect on body weight maintenance after weight loss. American Journal of Clinical Nutrition 2009; 89: 822-8.

4. Pories WJ. Bariatric surgery: Risks and rewards. Journal of Clinical Endocrinology and Metabolism 2008; 93:589-96.

5. Cabrera C, Artacho R, Gimenez R. Beneficial effects of green tea: A review. Journal of the American College of Nutrition 2006; 25(2): 79-94. 
6. Auger C, Mullen W, Hara Y, Crozier A. Bioavailability of polyphenon E Flavan-3-ols in humans with an ileostomy. Journal of Nutrition 2008; 138: 1535-42.

7. Ikeda I. Review article: Multifunctional effects of green tea catechins on prevention of the metabolic syndrome. Asia Pacific Journal of Clinical Nutrition 2008; 17: 273-4.

8. Meschino JP. Green tea catechins reduce body fat and LDL oxidation. Dynamic Chiropractic Canada 2009; 2: 1-3.

9. Wang H, Wen Y, Du Y, et al. Effects of catechin enriched green tea on body composition. Obesity 2010; 18: 773-8.

10. Zaveri NT. Green tea and its polyphenolic catechins: Medicinal uses in cancer and noncancer applications. Life Sciences 2006; 78: 2073-8.

11. Adak M, Gabar MA. Green tea as a functional food for better health: A brief review. Research Journal of Pharmaceutical, Biological and Chemical Sciences 2011; 2: 645-59.

12. Koo MW, Cho CH. Review: Pharmacological effects of green tea on the gastrointestinal system. European Journal of Pharmacology 2004; 500: 177-82.

13. Lee J, Li Y, Li C, Li D. Review article: Natural products and body weight control. North American Journal of Medical Science 2011; 3:13-8.

14. Rains TM, Agarwal S, Maki KC. Antiobesity effects of green tea catechins: A mechanistic review. Journal of Nutritional Biochemistry 2011; 22:1-6.

15. Lin YS, Tsai YJ, Tsay JS, Lin JK. Factors affecting the levels of tea polyphenols and caffeine in tea leaves. Journal of Agricultural and Food Chemistry 2003; 51: 1864-5.

16. Fernandez PL, Pablos F, Martin MJ, Gonzalez AG. Study of catechins and xanthine tea profiles as geographical traces. Journal of Agricultural and Food Chemistry 2002; 50: $1833-9$.

17. Phung OJ, Baker WL, Matthews LJ, Lanosa M, Thorne A, Coleman CI. Effect of green tea catechins with or without caffeine on anthropometric measures: A systematic review and meta-analysis. American Journal of Clinical Nutrition 2010; 91: 73-80.

18. Stangl V, Lorenz M, Stangl K. Review: The role of tea and tea flavonoids in cardiovascular health. Molecular Nutrition and Food Research 2006; 50: 218-26.

19. Chow HHS, Cai Y, Alberts DS, et al. Phase I pharmacokinetic study of tea polyphenols following single-dose administration of epigallocatechin gallate and polyphenon E. Cancer Epidemiol Biomarkers and Prevention 2001; 10: 53-8.

20. Nagao T, Hase T, Tokimitsu I. A Green tea extract high in catechins reduces body fat and cardiovascular risks in humans. Obesity 2007; 15: 1473-82.

21. Erguder IB, Namuslu M, Sozener U, et al. Effects of aqueous green tea extract on activities of DNA turn-over enzymes in cancerous and non-cancerous human gastric and colon tissues. Alternative Therapies in Health and Medicine 2008; 14(3): 30-3.

22. Hsu SP, Wu MS, Yang CC, et al. Chronic green tea extract supplementation reduces hemodialysis enhanced production of hydrogen peroxide and hypochlorous acid, atherosclerotic factors, and proinflammatory cytokines. American Journal of Clinical Nutrition 2007; 86: 1539-47.

23. Shimizu M, Fukutomi Y, Ninomiya M, et al. Green tea extracts for the prevention of metachronous colorectal adenomas: A pilot study. Cancer Epidemiol Biomarkers and Prevention 2008; 17: 3020-5.

24. Chen Z, Zhu QY, Tsang D, HuangY. Degradation of green tea catechins in tea drinks. Journal of Agricultural and Food Chemistry 2001; 49(1): 477.

25. Henning SM, Fajardo-Lira C, Lee HW, Youssefian AA, Go VLW, Heber D. Catechin content of 18 teas and a green tea extract supplement correlates with the antioxidant capacity. Nutrition and Cancer 2003; 45(2): 226-35.

26. Khokhar S, Magnusdottir SGM. Total phenol, catechin, and caffeine contents of teas commonly consumed in the United Kingdom. Journal of Agricultural and Food Chemistry 2002; 50(3): 565-66.

27. Nagao T, Komine Y, Soga S, et al. Ingestion of a tea rich in catechins leads to a reduction in body fat and malondialdehyde-modified LDL in men. American Journal of Clinical Nutrition 2005; 81: 122-8.

28. Now: Green tea extract 400 mg-100 caps. (Accessed January 5, 2012, athttp://www.nowfoods.com/Supplements/ Products-by-Category/Herbs-Mushrooms/Extracts/ M003173.htm).

29. Nature's way: Green tea standardized. (Accessed January 5, 2012, athttp://www.naturesway.com/Products/Herbs/ 61800-Green-Tea-Standardized.aspx).

30. Jarrow formulas: Green tea. (Accessed January 9, 2012, athttp://www.jarrow.com/product/294/Green_Tea).

31. Natrol: Weight management. (Accessed January 9, 2012, athttp://www.natrol.com/prod_weight.aspx?prod=128).

32. Manning J, Roberts JC. Analysis of catechin content of commercial green tea products. Journal of Herbal Pharmacotherapy 2003; 3(3): 19-32.

33. Chantre P, Lairon D. Recent findings of green tea extract AR25 (Exolise) and its activity for the treatment of obesity. Phytomedicine 2002; 9: 3-8.

34. Harada U, Chikama A, Saito S, et al. Effects of the long term ingestion of tea catechins on energy expenditure and dietary fat oxidation in healthy subjects. Journal of Health Science 2005; 51: 248-52.

35. Venables MC, Hulston CJ, Cox HR, Jeukendrup AE. Green tea extract ingestion, fat oxidation, and glucose tolerance in healthy humans. American Journal of Clinical Nutrition 2008; 87: 778-84.

36. Zhang R, Xiao W, Wang X, Wu X, Tian W. Novel inhibitors of fatty-acid synthase from green tea (Camellia sinensis Xihu Longjing) with high activity and a new reacting site. Biotechnology and Applied Biochemistry 2006; 43: 1-7.

37. Yeh CW, Chen WJ, Chiang CT, Lin-Shiau SY, Lin JK. Suppression of fatty acid synthase in MCF-7 breast cancer cells by tea and tea polyphenols: A possible mechanism for their hypolipidemic effects. Pharmacogenomics Journal 2003; 3: 267-76. 
38. Pierro FD, Menghi AB, Barreca A, Lucarelli M, Calandrelli A. GreenSelect ${ }^{\circledR}$ phytosome as an adjunct to a low-calorie diet for treatment of obesity: A clinical trial. Alternative Medicine Review 2009; 14: 154-9.

39. Hursel R, Westerterp-Plantenga MS. Review: Thermogenic ingredients and body weight regulation. International Journal of Obesity 2010; 34: 659-67.

40. Dawling S, Roodi N, Mernaugh RL, Wang X, Parl FF. Catechol-O-Methyltransferase (COMT)-mediated metabolism of catechol estrogens: Comparison of wild-type and variant COMT isoforms. Cancer Research 2001; 61: 6716-22.

41. Chow HHS, Haki, IA, Vining DR, et al. Effects of dosing condition on the oral bioavailability of green tea catechins after single-dose administration of polyphenon $\mathrm{E}$ in healthy individuals. Clinical Cancer Research 2005; 11: 4627-33.

42. Wu C, Lu F, Chang C, Chang T, Wang R, Chang C. Relationship among habitual tea consumption, percent body fat, and body fat distribution. Obesity Research 2003; 11: 1088-94.

43. Dulloo AG, Duret C, Rohrer D, et al. Efficacy of a green tea extract rich in catechin polyphenols and caffeine in increasing 24-h energy expenditure and fat oxidation in humans. American Journal of Clinical Nutrition 1999; 70: 1040-4.

44. Ota N, Soga S, Shimotoyodome A, et al. Effects of combination of regular exercise and tea catechins intake on energy expenditure in humans. Journal of Health Science 2005; 51: 233-6.

45. Boschmann M, Thielecke F. The effects of Epigallocatechin3-Gallate on thermogenesis and fat oxidation in obese men: A pilot study. Journal of the American College of Nutrition 2007; 26: 389S-95S.

46. Berube-Parent S, Pelletier C, Dore J, Tremblay A. Effects of encapsulated green tea and Guarana extracts containing a mixture of epigallocatechin-3-gallate and caffeine on $24 \mathrm{~h}$ energy expenditure and fat oxidation in men. British Journal of Nutrition 2005; 94: 432-56.

47. Hill AM, Coates AM, Buckley JD, Ross R, Thielecke F, Howe PRC. Can EGCG reduce abdominal fat in obese subjects. Journal of the American College of Nutrition 2007; 26: 396S-401S

48. Hsu C, Tsai T, Kao Y, Hwang K, Tseng T, Chou P. Effect of green tea extract on obese women: A randomized, doubleblind, placebo-controlled clinical trial. Clinical Nutrition 2008; 27: 363-8.

49. Kajimoto O, Kajimoto Y, Yabune M, et al. Tea catechins with a galloyl moiety reduce body weight and fat. Journal of Health Sciences 2005; 51:161-70.

50. Bajerska J, Jeszka J, Tarnowska AK, Czlapka-Matyasik $M$. The effect of green and oolong tea extracts supplementation on body composition in wrestlers. Pakistan Journal of Nutrition 2010; 9: 696-700.

51. Yang CS, Chen L, Lee MJ, Balentine D, Kuo C, Schantz SP. Short communication: Blood and urine levels of tea catechins after ingestion of different amounts of green tea by human volunteers. Cancer Epidemiology, Biomarkers and Prevention 1998; 7: 351-4.

52. Maki KC, Reeves MS, Farmer M, et al. Green tea catechin consumption enhances exercise-induced abdominal fat loss in overweight and obese adults. Journal of Nutrition 2009; 139: 264-9.

53. Stendell-Hollis NR, Thomson CA, Thompson PA, et al. Green tea improves metabolic biomarkers, not weight or body composition: A pilot study in overweight breast cancer survivors. Journal of Human Nutrition and Dietetics 2010; 23: $590-8$.

54. Diepvens K, Kovacs EMR, Vogels N, Westerterp-Plantenga MS. Metabolic effects of green tea and of phases of weight loss. Physiology and Behavior 2006; 87: 185-91.

55. Kovacs EMR, Lejeune MPGM, Nijs I, WesterterpPlantenga MS. Effects of green tea on weight maintenance after body-weight loss. British Journal of Nutrition 2004; 91:431-7.

56. Van het Hof KH, Kivits GAA, Weststrate JA, Tijburg LBM. Bioavailability of catechins from tea: The effect of milk. European Journal of Clinical Nutrition 1998; 52: 356-9.

57. Chow HHS, Cai Y, Hakim IA, et al. Pharmacokinetics and safety of green tea polyphenols after multiple-dose administration of epigallocatechin gallate and polyphenon E in healthy individuals. Clinical Cancer Research 2003; 9: 3312-8.

58. Donovan JL, Chavin KD, Devane CL, et al. Green tea (Camellia sinensis) extract does not alter cytochrome P450 3A4 OR 2D6 activity in healthy volunteers. Drug Metabolism and Disposition 2004; 32: 906-8.

59. Chow HHS, Hakim IA,Vining DR, et al. Effects of repeated green tea catechin administration on human cytochrome P450 activity. Cancer Epidemiology Biomarkers and Prevention 2006; 15: 2473-6.

60. Frank J, George TW, Lodge JK, et al. Daily consumption of an aqueous green tea extract supplement does not impair liver function or alter cardiovascular disease risk biomarkers in healthy men. Journal of Nutrition 2009; 139: 58-62.

61. Inoue M, Kurahashi N, Iwasaki M, et al. Effect of coffee and green tea consumption on the risk of liver cancer: Cohort analysis by hepatitis virus infection status. Cancer Epidemiological Biomarkers and Prevention 2009; 18(6): 1746-53.

62. Jin X, Zheng R, Li Y. Green tea consumption and liver disease. Liver International 2008; 28(7): 990-6.

63. Sing MF, Yang W, Gao S, Gao J, Xiang Y. Epidemiological studies of the association between tea drinking and primary liver cancer: a meta-analysis. European Journal of Cancer Prevention 2011; 20: 157-65.

64. Arab L, Liu W, Elashoff D. Green and black tea consumption and risk of stroke-A meta analysis. Stroke 2009, 1786-92.

65. Layher-Jr JW, Poling JS, Ishihara M, Asadi P, Manilla JA, Puett D. A possible effect of concentrated oolong tea causing transient ischemic attack like-symptoms. Journal of Medical Research 2013; 3(4): 2157-72. 
66. Molinaari M, Watt KDS, Kruszyna T, Nelson R, Walsh M, Huang WY, Nashan B, Peltekian. Acute liver failure induced by green tea extracts: case report and review of the literature. Transplantation 2006; 12: 1892-5.

67. Bonkoysky HL. Hepatotoxicity associated with supliments containing Chinese green tea (Camellia sinensis). Annals of Internal Medicine 2006; 144: 68-71.

68. Stevens T, Qadri A, Zein NN. (2005). Two patients with acute injury associated with use of the herbal weight loss supplement hydroxycut. Annals Internal Medicine 2005; 142: $477-8$.

69. Jimenez-Encarnacion E, Rios G, Munoz-Mirabal A, Vila LM. Euforia-induced acute hepatitis in a patient with scleroderma. British Medical Journal - case reports 2012.
70. Weinstein DH, Twaddell WS, Raufman JP, Phiosophe B, Mindikoglu AL. SlimQuick associated hepatotoxicity in a woman with alpha-1 antitrypsin heterozgosity. World Journal of Hepatology 2012; 4: 154-7.

71. Krishna RY, Mittal V, Grewal P, Fiel M, Schiano T. Acute liver failure caused by 'fat burners' and dietary supplements: a case report and literature review. Canadian Journal of Gastroenterology 2011; 25: 157-60.

72. Chen GC, Ramanathan VS, Law D, Funchian P, Chen GC, French S, Shlopoy B, et al. Acute liver injury induced by weight loss herbal supplements. World Journal of Hepatology 2010; 2: 410-5.

73. Rashid NN, Grant J. Hydroxycut hepatotoxicity. Medical Journal of Australia 2010; 192: 173-4. 